\title{
Influence of ustekinumab on body weight of patients with psoriasis: an initial report
}

\author{
Agnieszka Owczarczyk-Saczonek, Waldemar Placek, Joanna Rybak-d’Obyrn, Ewa Wygonowska
}

Department and Clinic of Dermatology, Sexually Transmitted Diseases and Clinical Immunology, Municipal Hospital, Olsztyn, Poland Head of Department: Prof. Waldemar Placek MD, PhD

Postep Derm Alergol 2014; XXXI, 1: 29-31

DOI: $10.5114 /$ pdia.2014.40656

\begin{abstract}
Introduction: Many recent epidemiological studies have shown the influence of treatment with anti-TNF- $\alpha$ on body mass of patients with psoriasis but there are no reports in the literature on the influence of ustekinumab on that parameter.

Aim: To review the effect of ustekinumab therapy on body weight in patients with psoriasis.

Material and methods: The examined group consisted of 11 patients with psoriasis treated at the Department and Clinic of Dermatology in Olsztyn. Patients' body mass and body mass index (BMI) were evaluated prior to the first administration of the ustekinumab dose and at week 28 of treatment (the day of the fourth dose).

Results: Body mass increase was determined in 7 patients (64\%), on average by $2.27 \mathrm{~kg}(p<0.05)$, and the BMI increased by $3.35 \%(p<0.1)$.

Conclusions: Observing a correlation between ustekinumab application and body mass increase, similar to the treatment with anti-TNF- $\alpha$ preparations, an attempt was undertaken at explaining that correlation by analysing the role of IL-12 and IL-23 in psoriasis pathogenesis. IL-12 and IL-23, by influencing the naïve lymphocytes T and stimulating their diversification towards Th1 and Th17, also, indirectly, cause an increase in TNF- $\alpha$ and other cytokines production (IL-2, IFN- $\gamma$, IL-17, IL-10, IL-22). Ustekinumab will then have a significant influence on decreasing the production of cytokines, which are important for metabolism and body mass.
\end{abstract}

Key words: psoriasis, ustekinumab, obesity, tumour necrosis factor $\alpha$, interleukin 12, interleukin 23.

\section{Introduction}

Numerous studies confirm the correlation between obesity and psoriasis. Hypotheses are even formulated that obesity may be a factor in development of psoriasis. Body mass index (BMI) $26-29 \mathrm{~kg} / \mathrm{m}^{2}$ increases the risk of psoriasis slightly while obesity $\left(\mathrm{BMI}>29 \mathrm{~kg} / \mathrm{m}^{2}\right)$ increases that risk by more than 2-fold [1]. Additionally, body mass reduction improves the development of the disease [2-4].

It is also found that in the case of obese patients, the therapy effectiveness decreases. Patients with psoriatic arthritis and accompanying obesity less frequently achieved the Minimal Disease Activity (MDA) under the influence of therapy [5]. It is also established that body mass reduction by $5-10 \%$ improves the therapeutic reaction of psoriatic lesions to treatment with cyclosporine A [6]. Similarly, in patients whose body mass increases during therapy, the efficacy of biological medical drugs is lower [7]. Hence, a recommendation of less caloric diet may be complementary in treatment of patients with psoriasis [6].

Until now, the influence of treatment with anti-TNF- $\alpha$ preparations on body mass of patients with psoriasis has been evaluated but there are no reports in the literature on the influence of ustekinumab on that parameter.

\begin{abstract}
Aim
Analysis of body mass and BMI in patients treated with ustekinumab for psoriasis was the aim of the paper.

\section{Material and methods}

The examined group consisted of 11 patients with psoriasis treated at the Department and Clinic of Dermatology, Sexually Transmitted Diseases and Clinical Immunology in Olsztyn. The patients satisfied the criterion of medium severe and severe psoriasis PASI > 10, BSA
\end{abstract}

Address for correspondence: Agnieszka Owczarczyk-Saczonek MD, PhD, Department and Clinic of Dermatology, Sexually Transmitted Diseases and Clinical Immunology, Municipal Hospital, Al. Wojska Polskiego 30, 10-595 Olsztyn, Poland, phone: +48 89678670 , fax: +48 89678 675, e-mail: aganek@wp.pl Received: 4.04.2013, accepted: 23.06.2013. 
$>10$ and DLQI $>10$ according to the EuCOTT (European Consensus Conference on Treatment Goals and Transitioning Treatments) [8]. Patients' body mass and BMI were evaluated prior to the first administration of the ustekinumab dose and at week 28 of treatment, i.e. on the day of administration of the fourth dose of the drug.

\section{Results}

Body mass increase was determined in 7 patients (64\%), on average by $2.27 \mathrm{~kg}(p<0.05)$, and the BMI increased by $3.35 \%(p<0.1)$ (Figure 1$)$.

Our results are similar to those reported by other authors evaluating body mass of patients with psoriasis treated with anti-TNF- $\alpha$ preparations at week 24 of therapy. Gisondi et al. observed the average body mass increase in patients receiving etanercept by $1.5 \pm 2.7 \mathrm{~kg}$ $(n=58)$, and those receiving infliximab by $2.5 \pm 3.3 \mathrm{~kg}$ $(n=40)(p=0.004)$. The control group consisted of patients treated with methotrexate, for whom no significant body mass changes were found [9]. Similarly, Renzo et al. showed the average body mass increase by 2.6 $\pm 3.2 \%$ in patients treated with etanercept $(n=28)$ and infliximab $(n=12)$ [10]. Saraceno et al. conducted the analysis of body weight for patients treated with antiTNF- $\alpha$ at week 48 of therapy. The average body mass

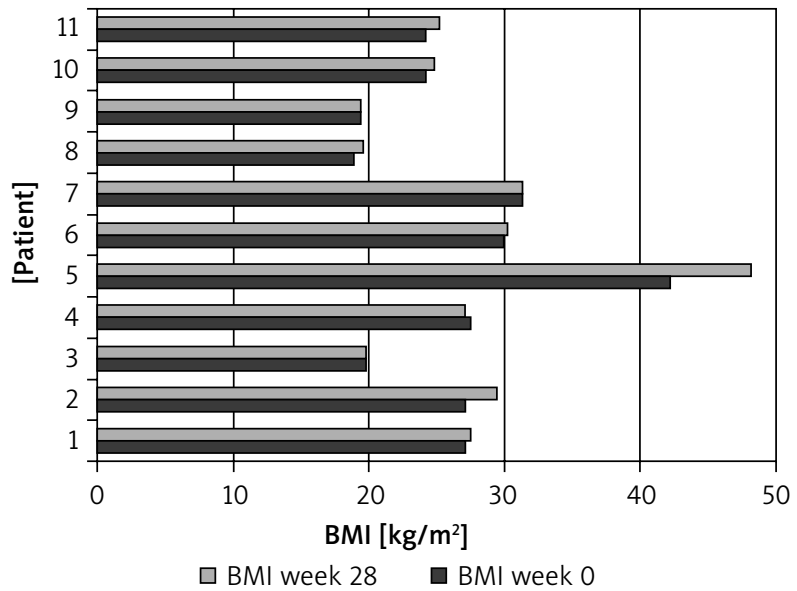

Figure 1. Analysis of body mass of 11 patients treated with ustekinumab at week 28

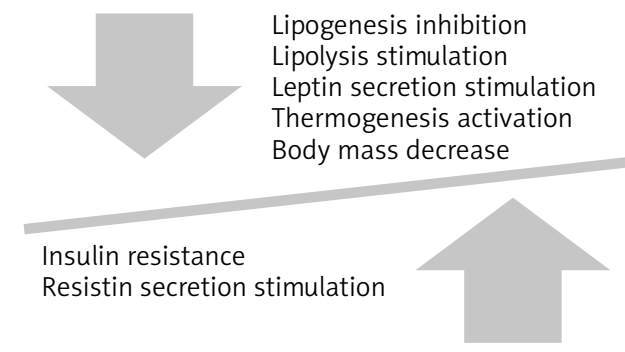

Figure 2. TNF- $\alpha$ influence on body mass increases for patients receiving infliximab were $1.54 \mathrm{~kg}$ ( $p=0.0001)$, adalimumab $-2.57(p=0.0014)$, and etanercept -2.18 ( $p=0.007)$ [11]. On the other hand, Prignano et al. observed no statistically significant body mass increase in patients receiving etanercept $(54 \%)(n=62)$ and infliximab (53\%) $(n=36)$ [12].

Observing the correlation between ustekinumab application and body mass increase, similar to the treatment with anti-TNF- $\alpha$ preparations, an attempt was undertaken at explaining that correlation by analysing the role of IL-12 and IL-23 in psoriasis pathogenesis. The IL-12 and IL-23, by influencing the naïve lymphocytes $T$ and stimulating their diversification towards Th1 and Th17, also, indirectly, cause an increase in TNF- $\alpha$ and other cytokines production (IL-2, IFN- $\gamma, \mathrm{IL}-17, \mathrm{IL}-10, \mathrm{IL}-22$ ) [13-15]. Ustekinumab will then have a significant influence on decreasing the production of TNF- $\alpha$ [16], which is of particular importance for metabolism and body mass [7].

The TNF- $\alpha$ influence on metabolism is highly complex. Physiologically increased synthesis of that cytokine probably represents one of the mechanisms limiting further body mass increase in obese people. In the case of obese people, macrophages of visceral fatty tissue produce twice as much TNF- $\alpha$ as in the case of slim persons [17-19]. The TNF- $\alpha$ stimulates leptin synthesis, which, acting on the hypothalamus, leads to decreasing appetite and food intake $[18,19]$. Moreover, by stimulating hypothalamus and increasing the activity of the sympathetic system, it stimulates thermogenesis increasing the energy expenditure [19]. The TNF- $\alpha$ also influences a muscular mass decrease (activation of ubiquitin and non-enzymatic proteolysis of muscle proteins) [20]. In the fatty tissue, stimulation of lipolysis and inhibition of lipogenesis as well as decreased synthesis of anabolic insulin-like growth factor 1 (IGF-1) are observed $[7,18,19]$. On the other hand, TNF- $\alpha$ is responsible for the phenomena supportive to obesity, such as insulin resistance development (inhibiting the activity of the insulin receptor and glucose transporting proteins GLUT-4), as well as secondary, compensational insulin level increase stimulating the hunger centre [19].

Hence, the application of preparations inhibiting the activity of TNF- $\alpha$ may directly (adalimumab, infliximab, etanercept) or indirectly (ustekinumab) contribute to a body mass increase in treated patients.

Briot et al. observed a body mass increase in patients with spondyloarthropathies (also psoriatic arthritis) treated with anti-TNF- $\alpha$ preparations. Nevertheless, the body mass increase concerned not only the fatty tissue but also the muscles and additionally bone mineralisation was observed. The increase in the insulin-like growth factor IGF-1, which shows anabolic activity was also observed [4]. Muscle tissue body mass increase might be caused by the return of the protein reserves. On the other hand, due to the patients' life quality improvement, they can return to normal life activity and integrate with the society [7] (Figure 2). 
The activity of ustekinumab is based mainly on decreasing the number of lymphocytes Th17, and hence IL-17. Currently, numerous studies prove the role of that cytokine in metabolism disorders, but that role is not fully known yet and the results of studies are controversial. Studies by Sumarac-Dumanovic et al. showed an increased concentration of cytokines dependent on lymphocytes Th17 (IL-17 and IL-23) in obese women, without an increase in concentration of cytokines related to lymphocytes Th1 (IL-12, IFN- $\gamma$ ) [21]. On the other hand, Zúníga et al. showed an inhibitory influence of IL-17 on adipogenesis and metabolism of glucose in mice. Its deficiency increases diet-induced obesity and accelerates fatty tissue accumulation [22]. Numerous studies suggest that Th17 and IL-17 represent the missing link between the inflammation condition, immunological reaction and obesity $[23,24]$. Moreover, it is found that the concentrations of TNF- $\alpha$ and IL-17 are closely correlated [25]. Hence, decreasing the concentration of TNF- $\alpha$ under the influence of therapy with ustekinumab, coupled with the decrease in the concentration of IL-17, may influence body mass increase in the patients.

Lymphocytes Th17 are also the source of IL-10, which mitigates inflammatory processes induced by TNF- $\alpha$, IL- 6 and IL-1 and has a protective influence on vascular endothelium in people suffering from diabetes $[25,26]$. It also has a significant influence on metabolic processes. Low levels of IL-10 are linked to the metabolic syndrome, BMI increase as well as insulin resistance and type 2 diabetes [27]. On the other hand, studies by Jung et al. showed an increase in IL-10 concentration in obese patients coupled with body mass reduction [26]. Hence, blocking of IL-10 secretion might predispose to body mass increase.

\section{References}

1. Baran A, Flisiak I, Chodynicka B. Role of selected adipokines in psoriasis [Polish]. Przegl Dermatol 2011; 98: 422-8.

2. Hamminga EA, van der Lely AJ, Neumann HA, et al. Chronic inflammation in psoriasis and obesity: implications for therapy. Med Hypotheses 2006; 67: 768-73.

3. Gottlieb AB, Dann F. Comorbidities in patients with psoriasis. Am J Med 2009; 122: 1150-9.

4. Briot K, Garnero P, Le Henanff A, et al. Body weight, body composition, and bone turnover changes in patients with spondyloarthropathy receiving anti-tumour necrosis factor alpha treatment. Ann Rheum Dis 2005, 64: 1137-40.

5. Di Minno MN, Peluso R, lervolino S, et al. Obesity and the prediction of minimal disease activity. A prospective study in psoriatic arthritis. Arthritis Care Res (Hoboken) 2013; 65: 141-7.

6. Gisondi P, Del Giglio M, Di Francesco V, et al. Weight loss improves the response of obese patients with moderate-to-severe chronic plaque psoriasis to low-dose cyclosporine therapy: a randomized, controlled, investigator-blinded clinical trial. Am J Clin Nutr 2008; 88: 1242-7.

7. Bardazzi F, Balestri R, Baldi E, et al. Correlation between BMI and PASI in patients affected by moderate to severe psoriasis undergoing biological therapy. Dermatol Ther 2010; 23: 14-9.
8. Mrowietz U, Kragballe K, Reich K, et al. Definition of treatment goals for moderate to severe psoriasis: a European consensus. Arch Dermatol Res 2011; 301: 1-10.

9. Gisondi P, Cotena C, Tessari G, et al. Anti-tumour necrosis factor-alpha therapy increases body weight in patients with chronic plaque psoriasis; retrospective cohort study. J Eur Acad Dermatol Venereol 2008; 22: 341-4.

10. Renzo LD, Saraceno R, Schipani C, et al. Prospective assessment of body weight and body composition changes in patients with psoriasis receiving anti-TNF-alpha treatment. Dermatol Ther 2011; 24: 446-51.

11. Saraceno R, Schipani C, Mazzotta A, et al. Effect of anti-tumour necrosis-alpha therapies on body mass index in patients with psoriasis. Pharmacol Res 2008; 57: 290-5.

12. Prignano F, Ricceri F, Pescitelli L, et al. Comparison of body weight and clinical-parameter changes following the treatment of plaque psoriasis with biological therapies. Curr Med Res Opin 2009; 25: 2311-6.

13. Gately MK, Renzetti LM, Magram J, et al. The interleukin-12/ interleukin-12-receptor system: role in normal and pathologic immune responses. Annu Rev Immunol 1998; 16: 495-521.

14. Kryczek I, Bruce AT, Gudjonsson JE, et al. Induction of IL-17+ $T$ cell trafficking and development by IFN-gamma: mechanism and pathological relevance in psoriasis. J Immunol 2008; 181: 4733-41.

15. Wilson NJ, Boniface K, Chan JR, et al. Development, cytokine profile and function of human interleukin 17-producing helper T cells. Nat Immunol 2007; 8: 950-7.

16. Nickoloff BJ, Nestle FO. Recent insights into the immunopathogenesis of psoriasis provide new therapeutic opportunities. J Clin Invest 2004; 113: 1664-75.

17. Argiles JM, Lopez-Soriano J, Busquets S, et al. Journey from cachexia to obesity by TNF. FASEB J 1997; 11: 743-5.

18. Gustafson B. Adipose tissue, inflammation and atherosclerosis. J Atheroscler Thromb 2010; 17: 332-41.

19. Olszanecka-Glinianowicz M, Zahorska-Markiewicz B, Żurakowski A, et al. Role of tumor necrosis factor-alfa in the control of metabolism [Polish]. Wiad Lek 2005; 58: 670-4.

20. Li YP, Lecker SH, Chen Y, et al. TNF-alpha increases ubiquitin- conjugating activity in skeletal muscle by up- regulating UbcH2/E22OK. FASEB J 2003; 17: 1048-57.

21. Sumarac-Dumanovic M, Stevanovic D, Ljubic A, et al. Increased activity of interleukin-23/interleukin-17 proinflammatory axis in obese women. Int J Obese 2009; 33: 151-6.

22. Zúńiga LA, Shen WJ, Joyce-Shaikh B, et al. IL-17 regulates adipogenesis, glucose homeostasis, and obesity. I Immunol 2010; 185: 6947-59.

23. Łuczyński W, Szypowska A, Bossowski A, et al. The assessment of CD4+CD161+ cells in the peripheral blood of children with type 1 diabetes and children with central obesity [Polish]. Pediatr Endocrinol 2011; 4 : 37-44.

24. Winer S, Paltser G, Chan Y, et al. Obesity predisposes to Th17 bias. Eur I Immunol 2009; 39: 2629-35.

25. Charles KA, Kulbe H, Soper R, et al. The tumor-promoting actions of TNF-alpha involve TNFR1 and IL-17 in ovarian cancer in mice and humans. J Clin Invest 2009; 119: 3011-23.

26. Jung SH, Park HS, Kim KS, et al. Effect of weight loss on some serum cytokines in human obesity: increase in IL-10 after weight loss. J Nutrit Biochem 2008; 19: 371-5.

27. Blüher M, Fasshauer M, Tönjes A et al. Association of interleukin-6, C-reactive protein, interleukin-10 and adiponectin plasma concentrations with measures of obesity, insulin sensitivity and glucose metabolism. Exp Clin Endocrinol Diabetes 2005; 113: 534-7. 